\title{
Rather yield than break: assessing the influence of human bone collagen content on heat-induced warping through vibrational spectroscopy
}

\author{
Ana R. Vassalo ${ }^{1}$; Eugénia Cunha ${ }^{1,2}$; Luís A. E. Batista de Carvalho ${ }^{3}$; David Gonçalves ${ }^{2,4,5}$ \\ ${ }^{1}$ Department of Life Sciences, University of Coimbra, Calçada Martim Freitas, 3000-456 Coimbra, Portugal \\ ${ }^{2}$ Laboratory of Forensic Anthropology, Department of Life Sciences, University of Coimbra, Calçada \\ Martim Freitas, 3000-456 Coimbra, Portugal \\ ${ }^{3}$ Unidade de I\&D Química-Física Molecular, Department of Chemistry, University of Coimbra, 3004-535, \\ Coimbra, Portugal. \\ ${ }^{4}$ LARC (DGPC) and LARC/CIBIO/InBIO, Rua a Bica do Marquês 2, 1300-087 Lisboa, Portugal \\ ${ }^{5}$ CIAS, Department of Life Sciences, University of Coimbra, Calçada Martim Freitas, 3000-456 Coimbra, \\ Portugal
}

Correspondent author: ana_rita_vassalo@hotmail.com

\begin{abstract}
Warping has been used to determine the pre-burning condition of human skeletal remains. In the literature, this modification has been associated more often with the burning of fleshed and green bones, but it also arises during the burning of dry bones. The objective of this paper was to assess if bone collagen content has a significant effect on the occurrence of warping in a sample of experimentally burned human bones.

The presence of collagen was analyzed in two different samples through a vibrational spectroscopy technology - FTIR. One of them was composed of 40 archaeological bones from the 17-20th centuries AD. The other one was composed of bones from 14 skeletons belonging to the 21st Century Identified Skeletal Collection. The results confirmed that the amide I band assigned to the collagen was much more intense in bones presenting heat-induced warping. Nonetheless, although significant $(\mathrm{p}=0.040)$, the collagen content was not as useful as other variables to the regression model we proposed for explaining warping. Factors such as the maximum temperature ( $\mathrm{p}<0.001)$ and burning time $(\mathrm{p}=0.001)$ contributed more significantly. Results demonstrated that the mere preservation of collagen is not enough to explain warping. Burning dynamics seem to have an important role as well although we failed to clearly document its specificities. Other factors such as the asymmetric distribution of collagen and other components within bone, the gravity force, the shape of the bone and the position in which it is burned may also play an important role on heatinduced changes and require further analysis.
\end{abstract}

Key-words: biological anthropology; forensic anthropology; FTIR; burned human bones; heat-inducedchanges; pre-burning condition 


\section{Introduction}

Heat-induced changes reduce the application and reliability of bioanthropological methods. Therefore, the study of remains burned in controlled experiments has been important in documenting the effects of heat on bones and in understanding how these changes affect the estimation of biological profiles, the assessment of injuries and the identification of skeletal diseases, as well as the determination of some of the circumstances surrounding death and the estimation of the pre-burning conditions of human remains [1]. In archaeological contexts, the latter is important to reconstruct past funerary practices since it may tell us if the burning was carried out on whole bodies, green bones or dry bones. In forensic settings, it may help to eliminate fire as a circumstance of death if a burning on dry bones is demonstrated to have happened. This paper focuses on this issue by implementing an experimental approach to better understand heatinduced warping, a feature that has been proposed as an indicator of the pre-burning condition of human remains $[1,2,6-11]$.

The pre-burning condition of the remains may not always be clear. In the absence of soft tissues, the use of other features to infer the pre-burning condition has been demonstrated to be quite helpful. For example, color pattern and fracture biomechanics in burned bone are very reliable indicators [2, 3]. However, these features may not always be present since no perimortem injury may have occurred or the remains may have been completely subjected to calcination and thus present a homogeneous and therefore less informative color pattern. In such cases, their usefulness is therefore lost. In addition, any heat-induced chromatic analyses may be jeopardized due to burial-related color changes. The representation of bones with labile joints [4] and the presence of objects suggestive of whole body burnings such as pacemakers or intrauterine devices [5] can also give some insight about the pre-burning condition of the remains but they are not entirely conclusive indicators. In addition, the anatomical position of the elements composing the skeleton may sometimes help to infer if it represents a primary or a secondary deposition, but the original setting may have been disturbed by post-depositional events such as the ones provided by animal scavenging, botanical activity, weathering or any attempt to move or conceal the body. Given the limitations of the indicators described above, others may be of additional help. Along with heat-induced fractures, warping has been used to estimate the pre-burning condition of remains [1, 2, 6-11]. It has been associated more often with the burning of corpses still displaying soft tissues [12,13), but can also arise during the burning of unfleshed human bones, although less frequently [5, 14, 15]

Some explanations for the appearance of warping have been proposed. Binford [13] suggested it might be the result of the contraction of muscle fibers in the bodies; Spenneman and Colley [14] preferred to put emphasis on a possible twisting caused by gas trapped inside the bone medullar canal; Thompson [16] argued that it may result from uneven contraction due to the periosteum anisotropic distribution of collagen; based on the latter hypothesis, Gonçalves et al. [5, 17] suggested that it could be dependent of the preservation of the collagen-apatite bonds. In brief, bones with well preserved collagen-apatite bonds have a greater elasticity and therefore, are more likely to deform $[5,17]$. However, no experimental research has been carried out so far to test this hypothesis. As a result, this paper attempted to solve this question, by assessing if the amount of collagen content (CC) in human bones subsequently subjected to experimental and controlled burning had any significant correlation with the heat-induced occurrence of warping. Along with CC, intensity of combustion (maximum temperature, burning time and temperature increment) [5, 18], 
sex $[17,19)$ age at death $[20,21])$ and burial period $[22,23]$ have been investigated since these have been suggested to have a significant role in the CC [24]. The experimental and controlled burning of archaeological human bones and of identified skeletons from the Coimbra $21^{\text {st }}$ Century Identified Skeletal Collection [25] allowed us to monitor all these variables and compare results between the two samples.

Fourier transform infrared spectroscopy (FTIR) was used to assess CC due to its easiness, quickness to yield results, low cost and to the fact that it requires only a small bone sample. It has been proved useful in the study of biological compounds, particularly in the assessment of the development, composition and quality of human bones [26, 27]. In the particular case of biological anthropology, its application has been important in investigations regarding the temperature estimation at which bones have been subjected to [28-31]. A FTIR spectrum obtained from bone samples provides information on the preservation of the inorganic component as well as the organic component [27, 32]. The signs attributable to bone components are visible in the wavelength region between 450 and $1800 \mathrm{~cm}^{-1}[26,33]$. As a proxy for CC, we used the amide I band visible at the $1625-1700 \mathrm{~cm}^{-1}$ region $[34,35]$. We therefore used these values to investigate its effect on the occurrence of heat-induced warping.

This may be the first step of obtaining a useful technique for the estimation of the pre-burning condition of human remains. Such technique would be critical to better reconstruct both the funeral behavior of past populations and the circumstances of death in forensic cases.

\section{Material and methods}

This study was carried out on two different samples. The first one was composed of 40 archaeological fragments of long bones from a civil cemetery of the Hospital de Santo António, located in Porto (Portugal). Its chronology ranges from the late $17^{\text {th }}$ to the early $20^{\text {th }}$ centuries. The second sample was composed of long bones from 14 individuals from the $21^{\text {st }}$ Century Identified Skeletal Collection housed at the Department of Life Sciences of the University of Coimbra [25]. The skeletons of this collection are from individuals who died very recently, i.e. in the last 20 years. Sex, age at death and burial period of each individual are known for the second sample but unknown for the archaeological sample. For practical purposes, the modern sample will henceforth be designated as the forensic sample. None of the samples was knowingly subjected to any chemical treatment, so it was assumed that no phenomenon - in addition to those that are depositional in nature - resulted in changes to the organic component of the bones. The details regarding the biological profile and the parameters of the experimental burning of both samples are listed in Tables 1 and 2.

Bones were submitted to an experimental and controlled burning in an electric oven Barracha K-3 threephased 14A. Maximum temperature, burning time and temperature increment were the controlled variables (Table 1). After burning, the human remains were analyzed macroscopically to check for unusual bending of the diaphyses and at their heat-fractured ends to assess if warping took place. The type of bone (e.g. clavicle; humerus; radius; ulna; femur; tibia; fibula) was also recorded as an additional variable for statistical testing to check if this had a significant effect on the occurrence of this specific HIC.

Median differences between the archaeological and forensic samples regarding the $\mathrm{CC}$ and median differences between the group of bones presenting warping and the group of bones not presenting it, regardless of sample membership, were investigated by using non-parametric Mann-Whitney tests. 
Differences between the archaeological and forensic samples regarding the frequency of warping were detected though a Pearson chi-square test.

The CC differences in bones from the same individual and in two regions of the same bone were also investigated. In the first case, no statistical test was used because of the small sample for each individual. Alternatively, we chose to determine if most bone CC values were within the $99 \%$ confidence interval calculated from the mean CC obtained from all bones of the same skeleton. This allowed us to check if the multiple CC values within each skeleton were consistent with each other. In the second case, we realized that a paired-sample statistical test or a correlation test would merely identify and compare means or linearities, which was not our objective. Since we intended to examine differences in a case by case basis and not between samples, we opted to calculate the relative difference between the two regions. We assumed the $10 \%$ threshold as a reference to identify substantial differences between both regions.

A multiple regression was used to assess if the variables sex, age at death, burial period and bone type had any significant effect on the CC. Since burial period was not known for the archaeological sample, we used a theoretical value to allow for comparisons between that and the forensic sample. Given the chronological range of the cemetery at the Hospital de Santo António, we calculated that the remains had at least been buried for 80 years ( 960 months) when they were finally exhumed. As a result, this value was used as the minimum burial period to enable comparison with the forensic sample. In addition, age at death and sex were not modeled in the case of the archaeological sample because it was not known. Although some fragments could indeed be anatomically identified, many of them could not so the inclusion of the bone type variable would have led to the reduction of the sample. For this reason, it was also not modeled on the archaeological sample.

Then, the isolated effect of the variables on the occurrence of warping was evaluated on the forensic sample. The application of Mann-Whitney tests allowed to assess the influence of the maximum temperature and the burial period. The isolated effects of burning time, increment of temperature and age at death were verified with Student's t-tests. The influence of sex and bone type was also investigated through the application of Pearson chi-squared tests. In an attempt to determine which of these factors intervened more significantly in the occurrence of warping in the forensic sample, we used a logistic regression modeling the following variables: maximum temperature, burning time, age at death, sex, burial period, type of bone and collagen content. Temperature increment was not modeled due to multicollinearity issues. A logistic regression was also used in the case of the archaeological sample but only by modeling maximum temperature, burning time and CC. Age at death, sex, type of bone and burial period were not modeled due to lack of information or, for the latter variable, due to its lack of variability since all samples were assumed to have been buried for 960 months. Differences in the occurrence of warping were also investigated within each of the archaeological and forensic samples by using Mann-Whitney and Student's $\mathrm{t}$-tests. The statistical analyses were carried out using the Statistical Package for the Social Sciences (SPSS), version 20 .

\section{Fourier Transform Infrared Spectroscopy (FTIR)}

The FTIR transmission spectra were recorded in a Bruker Optics Vertex 70 FTIR spectrometer purged by $\mathrm{CO}_{2}$-free dry air, in the $400-4000 \mathrm{~cm}^{-1}$ range of the wavelength. $\mathrm{A} \mathrm{KBr}$ beamsplitter and a liquid nitrogen 
cooled Mercury Cadmium Telluride (MCT) detector were used. Each spectrum was composed of 128 scans, with $2 \mathrm{~cm}^{-1}$ resolution and 3-Term Blackman-Harris apodization. The error in wavenumbers was estimated to be less than $1 \mathrm{~cm}^{-1}$.

Two small samples from the proximal and distal regions were collected from each bone before experimental burning. From each sample, $1.0 \mathrm{mg}$ was weighed and mixed with $100 \mathrm{mg}$ of solid $\mathrm{KBr}$ solvent (Sigma-Aldrich, FTIR grade). From this $1 \%(w / w)$ mixture, $50 \mathrm{mg}$ (corresponding to $0.5 \mathrm{mg}$ of sample) were used to obtain transparent discs ( $3 \mathrm{~mm}$ pellets) using a hand press. The analysis was performed between 450-1800 $\mathrm{cm}^{-1}$, where the most characteristic bands assigned to the vibrational modes from the bone major components are known to occur [26, 33]. The intensity of the bands was measured in the absorbance mode through calculation of the maximum value (peak height) after spectra baseline correction and normalization (relative to the phosphate band at $c a .1035 \mathrm{~cm}^{-1}$ ). Opus software (Bruker) was used to process the spectra.

\section{Results}

Representative FTIR spectra from bone samples are presented in figure 1. Briefly, in the $500-650 \mathrm{~cm}^{-1}$ spectral region, bands corresponding to the out-of-plane bending vibrations of the phosphate ions $\left(\mathrm{PO}_{4}{ }^{3-}\right)$, present in the mineral portion of the bones $\left[\mathrm{Ca}_{10}\left(\mathrm{PO}_{4}\right)_{6}(\mathrm{OH})_{2}\right.$, hydroxyapatite], are clearly seen, while in the $900-1200 \mathrm{~cm}^{-1}$ interval, signals due to the stretching vibrational modes of the $\mathrm{PO}_{4}{ }^{3-}$ are detected as the most intense FTIR features [33, 36, 37]. In turn, in the 1330-1530 $\mathrm{cm}^{-1}$ range, bands assigned to the stretching modes of the carbonate ions $\left(\mathrm{CO}_{3}{ }^{2-}\right)$ are detected, owing to the replacement of some of the hydroxyapatite anions, either phosphate or hydroxyl, by carbonate ones. Finally, bands assignable to amide groups occur on the 1200-1800 $\mathrm{cm}^{-1}$ spectral region: amide I $\left(1625-1700 \mathrm{~cm}^{-1}\right)$, amide II $\left(1450-1650 \mathrm{~cm}^{-1}\right)$ and amide III $\left(1200-1305 \mathrm{~cm}^{-1}\right)$ [26, 33, 37]. In this work, the ratio between the intensities of the amide I, at $c a .1660 \mathrm{~cm}^{-1}$, and $\mathrm{PO}_{4}{ }^{3-}$ antisymmetric stretching bands, near $1030 \mathrm{~cm}^{-1}$, was used to assess collagen content [38].

FTIR spectra show marked differences between the archaeological and forensic samples, particularly in the intensity of the bands corresponding to the organic portion of the bone. In fact, the spectra of forensic bones presented much more intense bands for the amide moieties I (collagen). Statistical tests indicated that the forensic sample (mean $=0.661 ; \mathrm{SD}=0.137$; median $=0.687$; range $=0.708$ ) had significantly more $\mathrm{CC}$ than the archeological sample (mean=0.141; $\mathrm{SD}=0.041$; median=0.131; range=0.206). Warping clearly occurred in $18 \%$ of archaeological bones (Fig. 2) despite their low amount of collagen and in $67 \%$ of forensic bones (Fig. 3). A significant difference in the frequency of warping between the two samples $(\chi 2=32.57$; $\mathrm{df}=2$; $\mathrm{N}=210 ; \mathrm{p}<0.001$ ) was found. The group of bones presenting warping (mean=0.641; SD=0.170; median=0.676; range=0.802) had significantly more $\mathrm{CC}$ than the group of bones lacking warping (mean=0.460; $\mathrm{SD}=0.276 ;$ median $=0.564 ;$ range $=0.811)$.

The analysis of relative differences in CC between two regions of the same bone showed that these differences can be as large as 50,60 and even 70\%. When evaluating the consistency of CC values among samples from multiple bones belonging to the same individual, only $29 \%$ to $75 \%$ of them fell inside the confidence interval of the skeleton mean. This demonstrated that the values varied quite substantially in function of the skeletal region from which the sample was taken. For example, variations of 0.135 (skeleton 
65) and 0.633 (skeleton 77) were observed. The linear regression model to predict CC and including the variables sex, age at death, burial period and type of bone was significant $(F=6.164 ; \mathrm{p}<0.01)$. However, it only explained $11 \%$ of the variance $\left(\mathrm{R}^{2}=0.105\right)$ and only age at death was found to have a significant contribution to the equation ( $\mathrm{p}<0.001)$ (Table 3).

Contrary to the result obtained by the linear regression, all variables but temperature increment were found to significantly influence bone warping when investigated in isolation on the forensic sample (Tables 4 and 5). The group of bones presenting warping was burned at significantly higher maximum temperatures ( $p<0.001)$, for a longer time ( $p=0.007)$, belonged more frequently to females $(p<0.001)$ and to older individuals ( $\mathrm{p}<0.001$ ) and presented a smaller burial period ( $\mathrm{p}<0.001)$. Also, chi-square testing showed that warping varied significantly at the 0.05 level according to the type of bone $(p=0.017)$ but this result was obtained exclusively on account of the clavicle. All types of bone beside this one showed observed counts that were similar to the expected counts.

The logistic regression model for the occurrence of warping in the forensic sample included the variables age at death, sex, maximum temperature, burning time, type of bone, $\mathrm{CC}$ and burial period (Table 6). The model was significant $(\chi 2=126.763 ; \mathrm{df}=7 ; \mathrm{N}=234 ; \mathrm{p}<0.001)$ and the Nagelkerke statistics $\left(\mathrm{R}^{2}\right.$ $=0.698$ ) showed that $70 \%$ of the variability found in the occurrence of warping in the forensic sample was explained by the model. Most of the variables significantly contributed to the equation at the 0.01 level, but age at death and CC contributed only at the 0.05 level. Burial period did not present a significant contribution to the equation at all.

Finally, the effect of maximum temperature, burning time and $\mathrm{CC}$ in the occurrence of warping was also evaluated in the archaeological sample through a logistic regression. However, the model was not significant $(\chi 2=0.491 ; \mathrm{df}=2 ; \mathrm{N}=40 ; \mathrm{p}<0.782 ; \mathrm{R} 2=0.020)$ and therefore was not able to predict heatinduced warping.

\section{Discussion}

Our results confirmed previous studies that documented the occurrence of heat-induced warping in dry bones $[5,15,17]$ in contrast to the observations made by other researchers who were only able to witness it on either fleshed or green bones [12, 13]. Recently, Gonçalves et al. [5, 17] hypothesized that a good preservation of collagen-apatite bonds and a gradual and slow increase in the burning temperature would allow the collagen to develop a contractile force required for the occurrence of warping and thumbnail fractures. This hypothesis was based on the previous work of Zioupos et al. [18] and Bartsiokas et al. [39] that led to the premise that contractile forces capable of moving the mineral fraction, which are developed when the bone is subjected to a more or less constant temperature, is only possible if the collagen-apatite bonds are well preserved. Therefore, this hypothesis put an emphasis on both the collagen preservation and on the dynamics of burning.

In fact, differences in the intensity of the bands corresponding to the organic portion of bone were found between the archaeological and forensic samples. Theoretically, post-depositional phenomena result in increasing loss of the organic component $[23,24]$ so it was expected that the more ancient archaeological bones had a smaller preservation of CC in comparison to the more recent forensic bones [40]. That would explain why the spectrum of forensic bones had a much more intense band of the amide I (collagen). 
However, the fact that $\mathrm{CC}$ had such a secondary role on the linear regression equation to predict warping was quite surprising. Although a significant effect was found when tested in isolation from other variables, its value as a predictor underperformed when a multiple regression model was built. That was possibly because the information provided by $\mathrm{CC}$ was already provided by one of the other variables. Nonetheless, no multicollinearity between the $\mathrm{CC}$ and other variables was found.

Results suggest that $\mathrm{CC}$ does not need to be very high to ensure warping and this was demonstrated by the wide range of values that led to it $(0.091$ to .894$)$. Nonetheless, a high CC is not equal to say that the collagen-apatite bonds were well preserved and these are crucial for warping to occur. Regrettably, our approach was not able to investigate this issue. Also, our results demonstrated that $\mathrm{CC}$ differences among bones and within a bone may be present and the site of warping did not always coincide exactly with the site of sampling. Therefore, our attempts to find a correlation may have been somewhat biased by this. Moreover, it should be taken into consideration that CC may be different between the convex and concave side in relation to the warping, and this could theoretically lead to warping due to differential contractile forces as well as affect its orientation. However, we cannot address this issue with certainty because samples were taken from only one side of the bone preventing us from doing CC comparisons between both sides. We do not think that anyone has ever tried to look at this before but it would constitute a good research focus in future studies.

As for the issue of the dynamics of combustion, the slow mean temperature increment adopted in this investigation yielded varied results. Actually, when tested in isolation, it had no significant effect on the occurrence of warping although temperature increment was indeed slightly lower for the group of bones presenting that heat-induced change. A more significant effect may have been prevented by the similar temperature increments that were adopted for all the burnings. Possibly, a larger range of temperature increments than the one used in this research could have provided us with a clearer picture of its true effect.

Looking at other variables, age at death provided unexpected results as well. Older individuals had more $\mathrm{CC}$ and were also more susceptible than younger individuals to warping, but the differences were negligible. This is at odds with the concept of collagen decreasing with age [18]. One explanation is related to the fact that the sample was poorly composed of young individuals so the age range was quite small not allowing for a true investigation of the age effect on the occurrence of warping. The results also seem to go against the theoretical premise that women have less collagen [19, 41] and should therefore be less susceptible to warping [17]. Females were actually more affected by warping than males although that effect had no significant contribution to the regression model for collagen content. Interestingly though, the burning of bones from female skeletons were subject to a lower temperature increment when compared to the bones from males. This may give some support to the hypothesis concerning the influence of burning dynamics on the occurrence of warping. As for the burial period, a significant effect on warping was also found but these results are not entirely reliable because, for the archaeological sample, this parameter was merely estimated as the minimum period. Nonetheless, this probably means that differences were probably even larger than the ones we modeled and thus more significant. Finally, regarding the type of long bone, a significant effect on the occurrence of warping was found therefore meaning that this feature may be dependent of the bone. In particular, the clavicle was much less affected by warping than expected. The reason for this lesser susceptibility to deform escapes us, but may be related to the particular shape of this 
bone when compared with other long bones or it may be due to a greater difficulty in assessing warping on it in comparison with other bones.

With respect to samples collected from the same bone, the results suggested that two regions showed considerable differences, so a single sample may not always represent the bone in its entirety. The same was observed for different types of bone from the same skeleton. In fact, studies seem to indicate a difference in the distribution of collagen in the individual, as well as in bone. Paschalis and colleagues [36] reported differences in the distribution of components within a bone and even within osteons. Turunen et al. [42] observed differences in composition and microstructure of the trabecular bone in different anatomical regions of the same individual. Post-depositional phenomena act in different ways over bones coming from the same skeleton thus potentially leading to differential rhythms of degradation [43]. It is then possible that unaltered areas of bone are sided along with microbiologically damaged regions [24]. The implications of this finding for future research are serious since it probably means that sampling cannot focus in a single location and must rather target several regions of the skeleton.

One important observation resulting from this investigation was the fact that no thumbnail fractures have been found in any of the bones that were experimentally burned. This was unexpected, since these heat-induced features have previously been documented to occur during the burning of dry bones [5, 17]. Gonçalves et al. [5] argued that warping and thumbnail fractures could be two sequential manifestations of the same event of bone contraction depending on the preservation of collagen-apatite bonds. According to this hypothesis, no changes would occur in cases of poor preservation, warping would occur in cases of well-preserved bonds while thumbnail fractures would occur in cases of less preserved bonds. However, our results do not give much support to this claim because only the two ends of this theoretical scope were found: warping and absence of heat-induced deformation. No intermediate stage, allegedly represented by thumbnail fractures, was found which strikes as odd given the large amount of bones that were tested. This would mean that none of the bones presented the hypothesized conditions leading to thumbnail fractures and this seems to be quite improbable. Therefore, the hypothesis is either wrong or differences between the burnings from this study and the burnings observed by Gonçalves et al. [5] were different enough to affect the occurrence of thumbnail fractures.

In summary, our investigation indicated that the $\mathrm{CC}$, although important, did not affect the manifestation of warping as critically as expected. Taking into consideration the regression analyses, factors such as the maximum temperature and burning time, apparently had a more crucial role. However, the fact that none of these variables have shown to be useful in predicting warping in the archaeological sample suggests that other variables are also important, such as age at death, sex and even other factors that were not taken into consideration in this research. That could be the case of the gravity force, the shape of the bone and the position in which it is burned so they require further analysis.

\section{Conclusion}

Additional investigations using the same FTIR approach on experimentally burned human bone samples and taking into account other spectral features such as the content of carbonate and the crystallinity index will be important to further clarify the results of this study. Also, other vibrational spectroscopy techniques such as Raman may provide additional benefits to this kind of investigation because it allows for non- 
intrusive analyses. This could therefore be more advantageous than FTIR for the spectral analysis of multiple sites within a bone since it has been established that the $\mathrm{CC}$ varies greatly not only at the bone level but also at the skeleton level. A great effort is still needed to identify and understand the variables that have a significant effect on warping before we can even envisage to create a technique that is able to estimate the pre-burning condition of human bones. The knowledge gained from this research is one step on that direction. If we succeed to achieve that goal, the implications for archaeology and forensic science will be major since it will allow us to better recreate the circumstances surrounding death.

Acknowledgments The authors acknowledge financial support from the Portuguese Foundation for Science and Technology - UID/MULTI/00070/2013, PTDC/IVC-ANT/1201/2014 and SFRH/BPD/84268/2012. We would also like to thank Calil Makhoul and João Coelho who helped on the preparation of the samples. We also thank Dr. Paula Marques and Ana Batista de Carvalho for their assistance in the FTIR spectra analysis.

Ethical standards This research does not infringe any Portuguese law.

Conflict of interest The authors declare that they have no conflict of interest.

\section{References}

1. Schmidt CW, Symes SA (eds) (2008) The analysis of burned human remains. Academic Press, Amsterdam

2. Symes S, Rainwater C, Chapman E, Gipson DR, Piper A (2008) Patterned thermal destruction of human remains in a forensic setting. In: Schmidt C, Symes S (eds) The analysis of burned human remains. Academic Press, London, pp 15-54

3. Symes SA, L'Abbé EN, Pokines JT, Yuzwa T, Messer D, Stromquist A, Keough N (2014) Thermal alteration to bone. In: Pokines JT, Symes SA (eds) Manual of forensic taphonomy. CRC Press, Boca Raton, pp 367-402

4. Duday H, Guillon M (2006) Understanding the circumstances of decomposition when the body is skeletonized. In: Schmitt A, Cunha E, Pinheiro J (eds) Forensic anthropology and medicine. Humana Press, Totowa, pp 117-158

5. Gonçalves D, Cunha E, Thompson TJU (2015) Estimation of the pre-burning condition of human remains in forensic contexts. Int J Legal Med. doi 10.1007/s00414-014-1027-8

6. Ubelaker DH, Rife JL (2007) The practice of cremation in the Roman-era cemetery at Kenchreai, Greece: the perspective from archeology and forensic science. Bioarchaeology of the Near East 1:35-57

7. Lemmers SAM (2012) Burned culture: osteological research into Urnfi eld cremation technology and ritual in the South of the Netherlands, Lunula. Archaeologia protohistorica 20:81-88

8. Harvig L, Kveiborg J, Lynnerup N (2013) Death in flames: human remains from a domestic house fire from Early Iron Age, Denmark. Int J Osteoarchaeol

9. Cavazzuti C, Salvadei L, (2014) I resti umani cremati dalla necropoli di Casinalbo. In: Cardarelli A (ed) La necropoli della terramara di Casinalbo. All'Insegna del Giglio, Firenze, pp 677-715

10. Silva FC (2015) The funerary practice of cremation at Augusta Emerita (Mérida, Spain) during High Empire: contributions from the anthropological analysis of burned human bone. In: Thompson TJU (ed) 
The archaeology of cremation: burned human remains in funerary studies. Oxbow Books, Oxford, pp $123-150$

11. Ulguim P (2015) Analysing cremated human remains from the southern Brazilian highlands: interpreting archaeological evidence of funerary practice at mound and enclosure complexes in the Pelotas River Valley. In: Thompson TJU (ed) The archaeology of cremation: burned human remains in funerary studies. Oxbow Books, Oxford, pp 173-212

12. Baby RS (1954) Hopewell cremation practices. In: Papers in archaeology, vol 1. Ohio Historical Society, Columbus, pp 1-7

13. Binford LR (1963) An analysis of cremations from three Michigan sites. Wis Archaeol 44:98-110

14. Spennemann DHR, Colley SM (1989) Fire in a pit: the effects of burning on faunal remains. Archaeozoologia 3:51-64

15. Whyte T (2001) Distinguishing remains of human cremations from burned animal bones. J Field Archaeol 28(3/4):437-448

16. Thompson TJU (2005) Heat-induced dimensional changes in bone and their consequences for forensic anthropology. J Forensic Sci 50(5):185-193

17. Gonçalves D, Thompson TJU, Cunha E (2011) Implications of heat-induced changes in bone on the interpretation of funerary behaviour and practice. J Archaeol Sci 38:1308-1313. doi:10.1016/j.jas.2011.01.006

18. Zioupos P, Currey JD, Hamer AJ (1999) The role of collagen in the declining mechanical properties of aging human cortical bone. J Biomed Mater Res 45(2):108-116

19. Curate F (2014) Osteoporosis and paleopathology: a review. J Anthropol Sci 92:119-146

20. Very JM, Gibert R, Guilhot B, Debout M, Alexandre C (1997) Effect of aging on the amide group of bone matrix, measured by FTIR spectrophotometry, in adult subjects deceased as a result of violent death. Calcified Tissue Int 60:271-275

21. Suda HK, Kajiwara M, Matsumoto N, Murayama H, Yamato H (2009) Characterization of apatite and collagen in bone with FTIR imaging. Mol Cryst Liq Cryst 505(1):64/[302]-69/[307]. doi:10.1080/15421400902942144

22. Bell LS, Skinner MF, Jones SJ (1996) The speed of post mortem change to the human skeleton and its taphonomic significance. Forensic Sci Int 82:129-140

23. Boaks A, Siwek D, Mortazavi F (2014) The temporal degradation of bone collagen: a histochemical approach. Forensic Sci Int. doi.org/10.1016/j.forsciint.2014.04.008

24. Collins MJ, Nielsen-Marsh CM, Hiller J, Smith CI, Roberts JP, Prigodich RV, Wess TJ, Csàpo J, Millard AR, Turner-Walker G (2002) The survival of organic matter in bone: a review. Archaeometry 44(3):383-394

25. Ferreira MT, Vicente R, Navega D, Gonçalves D, Curate F, Cunha E (2014) A new forensic collection of 21st Century Identified Human Skeletons housed at the University of Coimbra, Portugal. Forensic Sci Int 245:202.e1-202.e5. dOI:10.1016/j.forsciint.2014.09.021

26. Carden A, Morris MD (2000) Application of vibrational spectroscopy to the study of mineralized tissues (review). J Biomed Opt 5(3):259-268. doi:10.1117\%2F1.429994 
27. Paschalis EP, Mendelsohn R, Boskey AL (2011) Infrared assessment of bone quality. Clin Orthop Relat Res 469:2170-2178. doi:10.1007/s11999-010-1751-4

28. Munro LE, Longstaffe FJ, White CD (2007) Burning and boiling of modern deer bone: effects on crystallinity and oxygen isotope composition of bioapatite phosphate. Palaeogeogr Palaeocl 249:90102. doi:10.1016/j.palaeo.2007.01.011

29. Thompson TJU, Gauthier M, Islam M (2009) The application of a new method of Fourier Transform Infrared Spectroscopy to the analysis of burned bone. J Archaeol Sci 36:910-914. doi:10.1016/j.jas.2008.11.013

30. Thompson TJU, Islam M, Bonniere M (2013) A new statistical approach for determining the crystallinity of heat-altered bone mineral from FTIR spectra. J Archaeol Sci 40:416-422. doi.org/10.1016/j.jas.2012.07.008

31. Ellingham STD, Thompson TJU, Islam M, Taylor G (2015) Estimating temperature exposure of burnt bone - a methodological review. Science and Justice. doi.org/10.1016/j.scijus.2014.12.002

32. Maspero E, Sala S, Fedi ME, Martini M, Papagni A (2011) A new procedure for extraction of collagen from modern and archaeological bones for 14C dating. Anal Bioanal Chem. doi:10.1007/s00216-0115252-4

33. Grunenwald A, Keyser C, Sautereau AM, Crubézy E, Ludes B, Drouet C (2014) Revisiting carbonate quantification in apatite (bio) minerals: a validated FTIR methodology. J Archaeol Sci 49:134-141. doi.org/10.1016/j.jas.2014.05.004

34. Bellamy LJ (1975) [1954] The infrared spectra of complex molecules, vol 1, 3rd edn. Chapman and Hall, New Fetter Lane, pp 231-262

35. Heredia A, Colin-Garcia M, Peña-Rico MA, Aguirre Beltrán LFL, Grácio J, Contreras-Torres FF, Rodríguez-Galván A, Bucio L, Basiuk VA (2013) Thermal, infrared spectroscopy and molecular modeling characterization of bone: an insight in the apatite-collagen type I interaction. Advances in Biological Chemistry 3:215-223. doi.org/10.4236/abc.2013.32027

36. Paschalis EP, DiCarlo E, Betts F, Sherman P, Mendelsohn R, Boskey AL (1996) FTIR microspectroscopic analysis of human osteonal bone. Calcified Tissue Int 59:480-487

37. Movasaghi Z, Rehman S, Rehman I (2008) Fourier Transform Infrared (FTIR) spectroscopy of biological tissues. Appl Spectrosc Rev 43:134-179. doi:10.1080/0570492070182904

38. Lebon M, Reiche I, Bahain JJ, Chadefaux C, Moigne AM, Fröhlich F, Sémah F, Schwarcz HP, Falguères C (2010) New parameters for the characterization of diagenetic alterations and heat-induced changes of fossil bone mineral using Fourier transform infrared spectrometry. J Archaeol Sci 37:2652276. doi:10.1016/j.jas.2010.03.024

39. Bartsiokas A (2000) The eye injury of King Philip II and the skeletal evidence from the Royal Tomb II at Vergina. Science 288:511-514. doi:10.1126/science.288.5465.511

40. Nagy G, Lorand T, Patonai Z, Montsko G, Bajnoczky I, Marcsik A, Mark L (2008) Analysis of pathological and non-pathological human skeletal remains by FT-IR spectroscopy. Forensic Sci Int $175: 55-60$

41. Brickley M (2002) An investigation of historical and archaeological evidence for age-related bone loss and osteoporosis. Int J Osteoarchaeol 12:364-371. Doi:10.1002/oa.635 
42. Turunen MJ, Prantner V, Jurvelin JS, Kroger H, Isaksson H (2013) Composition and microarchitecture of human trabecular bone change with age and differ between anatomical locations. Bone 54:118-125. doi.org/10.1016/j.bone.2013.01.045

43. Price TD, Blitz J, Burton J, Ezzo JA (1992) Diagenesis in prehistoric bone: problems and solutions. J Archaeol Sci 19:513-529 


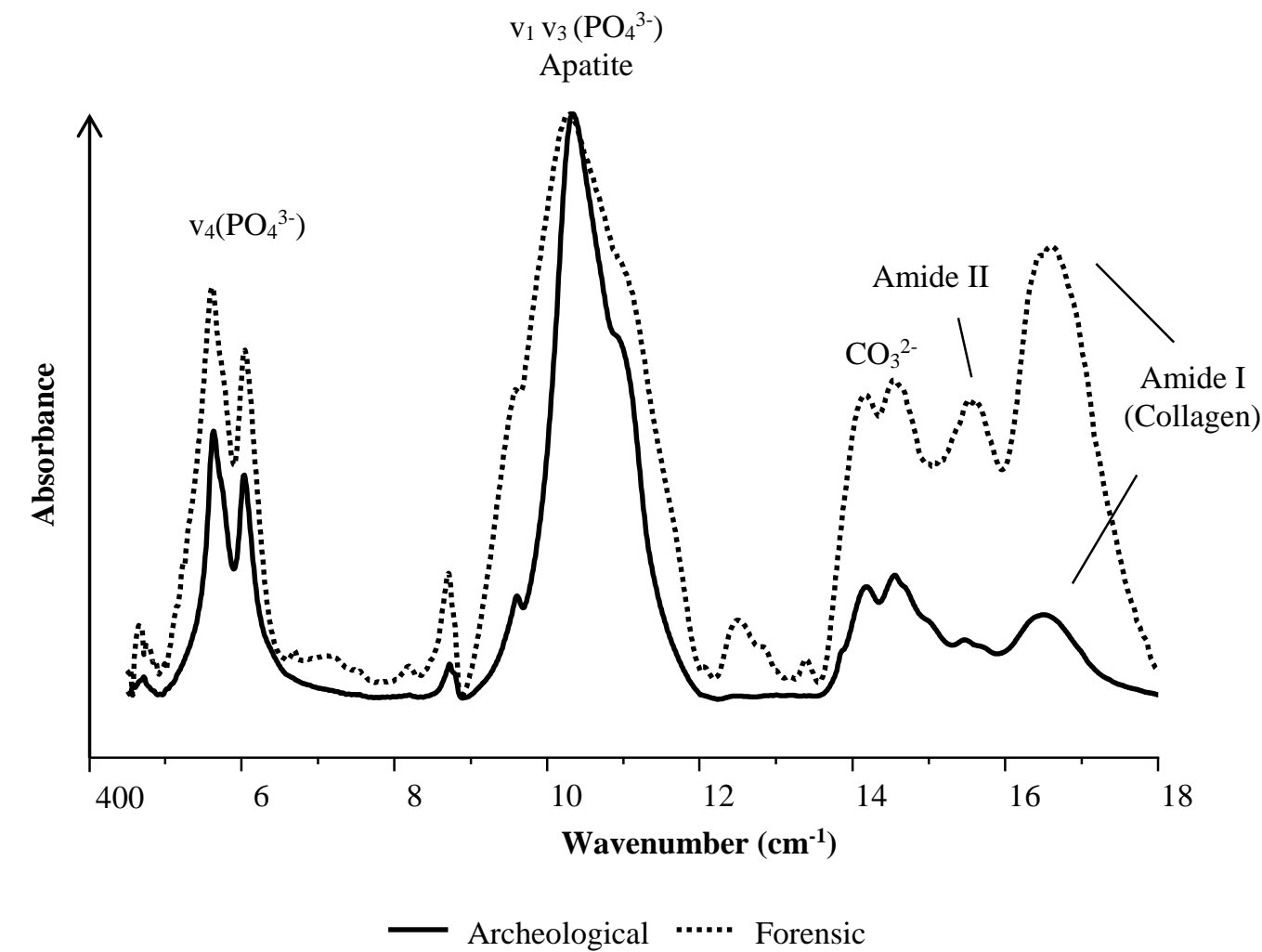

Fig. 1 FTIR spectra of the archaeological bone 16 and FTIR spectra of the humerus bone from the individual 65 from the 21st Century Identified Skeletal Collection.

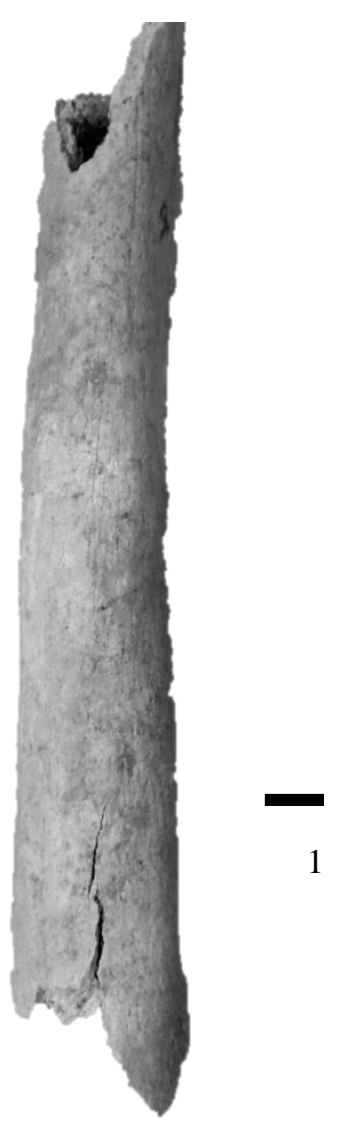

Fig. 2 Comparison between the unburned (left) and the heat-induced warped (right) archaeological bone 16. The bone displayed warping after burning that lasted $180 \mathrm{~min}$ and reached a maximum temperature of $900{ }^{\circ} \mathrm{C}$ 


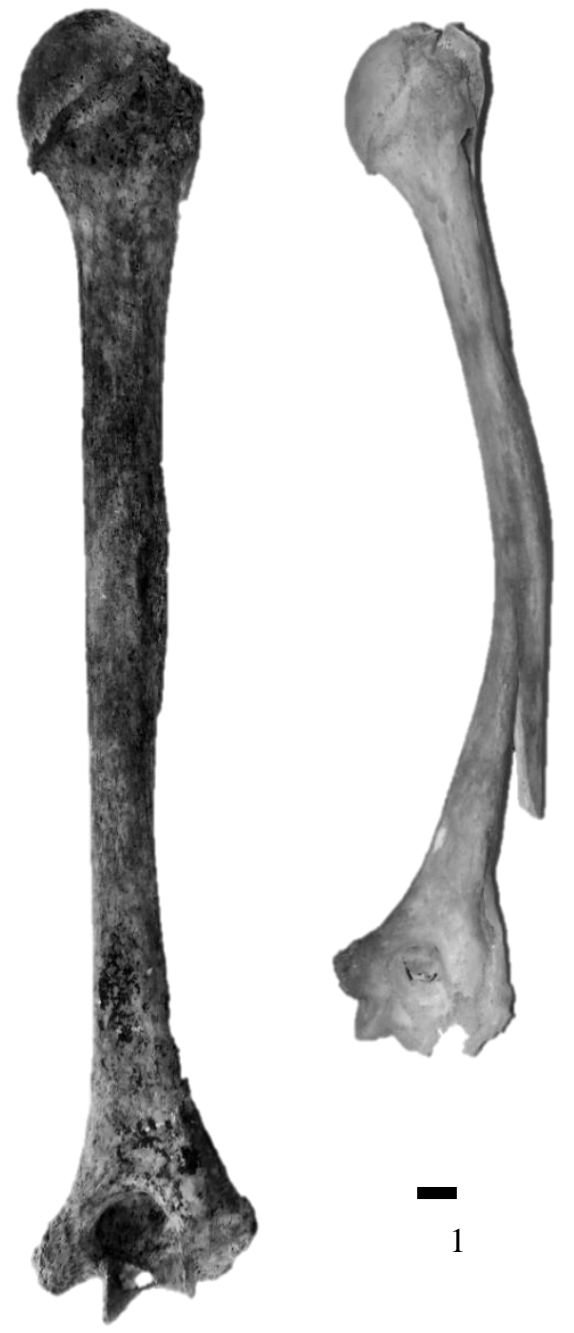

Fig. 3 Comparison between an unburned humerus (left) and a heat-induced warped humerus (right) from the 21st Century Identified Skeletal Collection. The burned humerus was from the individual 65 (an 81year-old female displaying warping after burning that lasted $116 \mathrm{~min}$ and reached a maximum temperature of $900{ }^{\circ} \mathrm{C}$ ) 
Table 1 Details of the archaeological sample for the minimum estimated burial period and the parameters of the experimental burning

\begin{tabular}{llll}
\hline Bone number & Burial period (months) & Maximum temperature $\left({ }^{\circ} \mathbf{C}\right)$ & $\begin{array}{l}\text { Burning time } \\
(\mathbf{m i n})\end{array}$ \\
\hline $\mathbf{1 - 6} / \mathbf{2 1 - 4 0}$ & $>960$ & 900 & 120 \\
$7-20$ & & 180 \\
\hline
\end{tabular}

Table 2 Details of the forensic sample regarding sex, age at death, burial period and the parameters of the experimental burning

\begin{tabular}{llllll}
\hline $\begin{array}{l}\text { Skeleton } \\
\text { number }\end{array}$ & Sex & $\begin{array}{l}\text { Age at } \\
\text { death }\end{array}$ & $\begin{array}{l}\text { Burial period } \\
\text { (months) }\end{array}$ & $\begin{array}{l}\text { Maximum } \\
\text { temperature }\left({ }^{\mathbf{0}} \mathbf{C}\right)\end{array}$ & $\begin{array}{l}\text { Burning } \\
\text { time }(\mathbf{m i n})\end{array}$ \\
\hline $\mathbf{2 4}$ & F & 80 & 73 & 800 & 120 \\
$\mathbf{2 6}$ & F & 90 & 74 & 900 & 195 \\
$\mathbf{2 9}$ & M & 74 & 74 & 800 & 110 \\
$\mathbf{3 2}$ & F & 81 & 74 & 800 & 120 \\
$\mathbf{3 5}$ & M & 75 & 71 & 900 & 180 \\
$\mathbf{4 3}$ & M & 70 & 72 & 800 & 150 \\
$\mathbf{4 9}$ & F & 85 & 76 & 850 & 120 \\
$\mathbf{5 0}$ & F & 89 & 72 & 900 & 120 \\
$\mathbf{5 1}$ & M & 70 & 73 & 900 & 126 \\
$\mathbf{5 3}$ & F & 77 & 73 & 800 & 172 \\
$\mathbf{5 7}$ & M & 85 & 84 & 900 & 105 \\
$\mathbf{6 4}$ & M & 87 & 73 & 800 & 75 \\
$\mathbf{6 5}$ & F & 81 & 72 & 900 & 116 \\
$\mathbf{7 7}$ & M & 68 & 114 & 500 & 75 \\
\hline
\end{tabular}

Table 3 Summary of the linear regression analysis for sex, age at death, burial period and bone type predicting the collagen content on the forensic sample

\begin{tabular}{lllllll}
\hline Variable & B & S.E. B & Beta & Sig. & Tolerance & VIF \\
\hline Sex & -0.005 & 0.023 & -0.018 & 0.832 & 0.704 & 1.420 \\
Age at death & 0.007 & 0.002 & 0.334 & 0.000 & 0.678 & 1.476 \\
Burial period & 0.000 & 0.001 & -0.025 & 0.741 & 0.858 & 1.166 \\
Bone type & 0.001 & 0.005 & 0.011 & 0.877 & 0.997 & 1.003 \\
\hline
\end{tabular}


Table 4 Effect of the variables sex and type of bone in the occurrence of warping on the forensic sample by applying a Pearson chi-square test $(\chi 2)$. Expected prevalence is presented in brackets

\begin{tabular}{|c|c|c|c|c|c|c|c|}
\hline \multirow{2}{*}{ Variabl } & & \multicolumn{3}{|c|}{ Warping } & \multirow{2}{*}{$\chi^{2}$} & \multirow{2}{*}{$\mathbf{p}$} & \multirow{2}{*}{ Phi } \\
\hline & & $\mathrm{n}$ & Present & Absent & & & \\
\hline \multirow{8}{*}{$\begin{array}{l}\text { Bone } \\
\text { type }\end{array}$} & Clavicle & 23 & $6(14.3)$ & $17(8.8)$ & \multirow{8}{*}{15.528} & \multirow{8}{*}{0.017} & \multirow{8}{*}{0.291} \\
\hline & Femur & 26 & $16(16.1)$ & $10(9.9)$ & & & \\
\hline & Fibula & 26 & $18(16.1)$ & $8(9.9)$ & & & \\
\hline & Humerus & 27 & $18(16.7)$ & $9(10.3)$ & & & \\
\hline & Radius & 28 & $20(17.3)$ & $8(10.7)$ & & & \\
\hline & Tibia & 26 & $16(16.1)$ & $10(9.9)$ & & & \\
\hline & Ulna & 28 & $20(17.3)$ & $8(10.7)$ & & & \\
\hline & Total & 184 & 114 & 70 & & & \\
\hline \multirow{3}{*}{ Sex } & Male & 82 & $40(55)$ & 42 (27) & \multirow{3}{*}{23.958} & \multirow{3}{*}{$<0.001$} & \multirow{3}{*}{-0.375} \\
\hline & Female & 88 & 74 (59) & 14 (29) & & & \\
\hline & Total & 170 & 114 & 56 & & & \\
\hline
\end{tabular}

Table 5 Descriptive and inferential statistics regarding the effect of maximum temperature, burning time, temperature increment, age at death and burial period on the occurrence of warping on the forensic sample

\begin{tabular}{|c|c|c|c|c|c|c|c|c|c|c|c|}
\hline $\begin{array}{l}\text { Burning } \\
\text { time } \\
\text { (min) }\end{array}$ & $\begin{array}{l}\text { Absent } \\
\text { Present }\end{array}$ & 121 & $\begin{array}{l}122.76 \\
134.93\end{array}$ & 30.03 & - & - & - & - & $-2.709^{b}$ & 0.007 & - \\
\hline $\begin{array}{l}\text { Temperatur } \\
\text { e increment } \\
\left({ }^{\circ} \mathrm{C} / \mathrm{min}\right)\end{array}$ & $\begin{array}{l}\text { Absent } \\
\text { Present }\end{array}$ & $\begin{array}{l}103 \\
121\end{array}$ & $\begin{array}{l}6.91 \\
6.68\end{array}$ & $\begin{array}{l}1.74 \\
1.33\end{array}$ & - & - & $\begin{array}{l}- \\
-\end{array}$ & - & $1.125^{b}$ & 0.262 & - \\
\hline $\begin{array}{l}\text { Burial } \\
\text { period } \\
\text { (month) }\end{array}$ & $\begin{array}{l}\text { Absent } \\
\text { Present }\end{array}$ & $\begin{array}{l}89 \\
121\end{array}$ & 402.18 & 430.64 & 73 & 72 & 960 & $\begin{array}{l}888 \\
889\end{array}$ & $3847.50^{a}$ & $<0.001$ & -0.248 \\
\hline
\end{tabular}

${ }^{\mathrm{a}}$ Mann-Whitney test; ${ }^{\mathrm{b}}$ Student t-test 
Table 6 Coefficients for the logistic regression analysis regarding the effect of maximum temperature, burning time, sex, age at death, burial period, bone type and collagen content on the occurrence of warping in the forensic sample

\begin{tabular}{lllll}
\hline Variable & B & S.E. B & Odds Ratio & Sig. \\
\hline Maximum temperature & 0.061 & 0.013 & 1.063 & $<0.001$ \\
Burning time & -0.048 & 0.015 & 0.953 & 0.001 \\
Sex & -4.859 & 0.967 & 0.008 & $<0.001$ \\
Age at death & -0.193 & 0.075 & 0.824 & 0.010 \\
Burial period & -0.045 & 0.112 & 0.956 & 0.691 \\
Bone Type & 0.412 & 0.137 & 1.510 & 0.003 \\
Collagen content & -4.180 & 2.036 & 0.015 & 0.040 \\
Constant & -21.195 & 7.330 & 0.000 & 0.004 \\
\hline
\end{tabular}

